\title{
Pagu e a narrativa da vida engajada
}

\section{Ana Luiza Mendes ${ }^{1}$}

Resumo: O presente artigo tem como objetivo fazer uma pequena análise da obra Parque Industrial, publicada em 1933 por Patrícia Galvão, comumente conhecida como Pagu. Tal análise desenvolve-se com base na crítica literária feminista, assim como na contextualização tanto dos temas abordados na obra, como o da sua publicação que, por vezes, confundem-se com a própria vida de Pagu, uma vez que ela no período da escrita do seu primeiro romance desenvolvia uma prática engajada extremamente ativa, o que pode colaborar para a compreensão do livro, que tinha o objetivo de ser revolucionário e que, mesmo o sendo, foi rechaçado e esquecido por décadas. $\mathrm{O}$ aspecto revolucionário do livro relaciona-se com o tom da crítica social nele desenvolvida, assim como com a linguagem pela qual essa crítica é veiculada, indicando-nos a vinculação com o movimento modernista em voga no período e no contexto de experiência de vida e de escrita de Pagu.

Palavras-chave: Parque Industrial; Pagu; modernismo; engajamento; escrita revolucionária

Abstract: This article aims to make a small analysis of the work Parque Industrial, published in 1933 by Patrícia Galvão, commonly known as Pagu. This analysis is based on feminist literary criticism, as well as on the contextualisation of the themes discussed in the book and his publication, which are sometimes confused with Pagu's own life, since in the time of the writing of her first novel she developed an extremely active engaged practice which can help to understand the book that had the purpose of being revolutionary and that even being it was rejected and forgotten for decades. The revolutionary aspect of the book is related to the tone of social criticism developed in it, as well as to the language by which this critique is conveyed, indicating the link with the modernist movement in vogue in the period and in the context of life and work of Pagu.

Key words: Parque Industrial; Pagu; modernism; engagement; revolutionary writing

${ }^{1}$ Doutoranda do Programa de Pós-graduação em História da UFPR.



ISSN 2317-4021 
"De fato, eu me arriscaria a supor que Anônimo, que escreveu tantos poemas sem assiná-los, foi muitas vezes uma mulher". ${ }^{2}$ Com essa frase, Virgínia Woolf (1882-1941) denunciava, em 1929, um fato por muito tempo consumado: às mulheres era restrito o mundo da autoria literária. Tal situação dava-se por condições sociais e ideológicas bem demarcadas que delimitavam de forma precisa o papel dos homens e das mulheres na sociedade. Estas, "naturalmente" inferiores, deveriam reger a vida doméstica, privada, reservada, enquanto aqueles, "naturalmente" superiores, seriam os responsáveis pelo ato criador, sendo que a criatividade artística era considerada como uma qualidade especificamente masculina. ${ }^{3}$ Entretanto, como é sabido, as mulheres utilizaram-se de subterfúgios para romper a barreira do protagonismo criativo falocêntrico e tornaram pública sua escrita, ainda que sob o anonimato ou sob um pseudônimo masculino.

$\mathrm{Na}$ época em que Virgínia escreveu já não havia a estrita necessidade das mulheres esconderem-se, porém, havia ainda a diferenciação e valorização das atividades desempenhadas por homens e mulheres. No caso da literatura podemos identificar tal fato ao analisarmos as compilações literárias, que são compostas por um número esmagador de autores masculinos. As autoras foram conscientemente retiradas da história de muitas literaturas e, quando mencionadas, eram afligidas com a crítica que considerava suas obras

${ }^{2}$ WOOLF, Virginia. Um teto todo seu. São Paulo: Círculo do Livro, s/d, p. 62.

${ }^{3}$ MOI, Toril. Teoria literaria feminista. Madri: Catedra, 1988.

Revista Vernáculo n. ${ }^{\circ} 41$ - primeiro semestre $/ 2018$

ISSN 2317-4021 
inferiores às dos homens e, portanto, não merecedoras de pertencerem ao cânone literário, fruto da sociedade e da ideologia patriarcais.

A constatação e a reprovação dessa postura foram desenvolvidas de forma mais contundente a partir das insurgências críticas postuladas pelo movimento feminista dos anos 1960 e 1970, que contribuiu para o desenvolvimento da crítica literária feminista, cujo objetivo é desafiar os pressupostos fundamentais da história e da crítica literária tradicionais ${ }^{4}$, incluindo os esforços para a sua inserção no ambiente acadêmico, que a recebeu com severos embates.

Assim, com a tese de doutorado de Kate Millet (1934-), Sexual Politics, de 1970, inaugura-se, então, uma postura de crítica literária e, em certa medida, social, uma vez que visa a desconstrução do caráter discriminatório das ideologias de gênero presentes nas relações sociais que são transpostas na literatura através das representações de personagens femininas submissas ao poder masculino, o que a autora define como "política sexual", uma política de força do poder do homem sobre a mulher que é perpetuada nas relações sociais e na literatura.

A partir desse pressuposto básico, a crítica literária feminista foi moldando-se em torno de vertentes de análises distintas que podem ser divididas em duas percepções: uma que se concentra na mulher

${ }^{4}$ WIECHMANN, Natália Helena. A crítica literária feminista e a autoria feminina. Vocábulo. Revista de letras e linguagens midiáticas. Ribeirão Preto, vol. IV. Disponível em: http://www.baraodemaua.br/comunicacao/publicacoes/vocabulo/volumeIV.html. Acesso em: 28/12/2016.

Revista Vernáculo n. ${ }^{\circ} 41$ - primeiro semestre $/ 2018$

ISSN 2317-4021 
enquanto leitora, perpassando pela análise das imagens e estereótipos da mulher na literatura, e outra que se ocupa da mulher enquanto escritora. A primeira relaciona-se com a análise sobre os papéis que são representados pelas mulheres, que tipos de temas se relacionam a elas e que pressuposições estão contidas em relação ao leitor acerca dessas representações, enquanto a segunda busca a recuperação de uma experiência e de uma "identidade feminina" e, como consequência, questiona o cânone literário masculino que define as noções de gênero, gosto e temas da produção literária, resgatando, assim, a produção de mulheres que foi silenciada ou excluída da história da literatura, voltando-se, pois, à questão da representação feminina a partir do conceito de opressão, da história social.

A segunda perspectiva pode ser tomada para a análise da obra Parque Industrial, de Patrícia Galvão (1910-1962), popularmente conhecida como Pagu, sobretudo as questões relacionadas à concepção de sua escrita que condiciona a investigação do seu romance.

Ainda que se insista em não relacionar ou em não tentar compreender a obra literária vinculada à vida do seu autor, no caso de Pagu esta tarefa torna-se difícil, uma vez que a sua escrita exprime um contexto de experiência específico que se confunde em certa medida com a História do Brasil e com a ideologia predominante na sua época, que entrelaça sua escrita e sua imagem pessoal. A obra da escritora não se encontra no cânone literário e por anos foi esquecida. Sua imagem, na grande maioria das vezes, perpassa pela da mulher louca. Assim

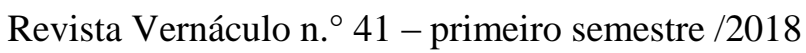

ISSN 2317-4021 
como na literatura, o estereótipo da loucura define a mulher que não se encaixa nos modelos de comportamento social estabelecidos.

Sobre sua imagem, a própria autora revela, em cartas direcionadas ao marido, Geraldo Ferraz, o seu incômodo pelo fato da imprensa super-relativizar a sua atuação na política:

Soube também que o meu nome era propalado aos quatro cantos e repetido com entusiasmo no meio dos proletários, o que era considerado pernicioso pelo Partido por se tratar de uma militante de origem pequeno-burguesa. Os jornais incentivavam isso com noticiário escandaloso em torno de minha pessoa. Eu era realmente a primeira comunista presa e, no Brasil, isso era assunto a ser explorado, principalmente não tratando de uma operária. Os comentários transformaram-se em lendas mentirosas, que exageravam minha atuação.

Daí partiu o boato de que eu tinha dominado a ação dos soldados que não tinham atirado por minha causa, etc. Todas essas coisas ridículas fizeram com que o Partido tomasse providências, pois só a organização e o nome da organização deveriam ser comentados. Sugeriu-se um manifesto e uma declaração minha. O manifesto só foi distribuído durante minha permanência na cadeia de Santos. Nele se acentuava a desordem provocada por mim, com intento provocador etc.

A humilhação foi dura, doeu demais, o meu orgulho e o que chamava dignidade pessoal sofreram brutalmente. Mas achei justa a determinação e aprovei o manifesto, disposta a todas as declarações ou fatos que exigisse de mim o meu Partido. ${ }^{5}$

${ }^{5}$ GALVÃo, Patrícia. Paixão Pagu: a autobiografia precoce de Patrícia Galvão. Geraldo Galvão Ferraz (Org). Rio de Janeiro: Agir, 2005, p. 91.

Revista Vernáculo n. ${ }^{\circ} 41$ - primeiro semestre $/ 2018$

ISSN $2317-4021$ 
Esse fragmento de uma carta escrita em 1940 e publicada em 2005 revela diversas informações pertinentes para compreender o mundo de Pagu. Primeiramente ela nos informa sobre ter sido a primeira comunista presa no Brasil. De fato, ela foi a primeira mulher presa política ${ }^{6}$, fato ocorrido em 1931 quando trabalhou como operária em Santos, proletarização exigida pelo Partido Comunista, no qual tentava se inserir.

Como podemos perceber no fragmento, o partido não estava satisfeito com as origens de Pagu, que, ainda que questionasse internamente os seus comandos, os colocava em prática para demonstrar o seu total envolvimento na causa. Assim, deixou Oswald de Andrade (1890-1954), seu primeiro marido, por recomendações do partido. Deixando Oswald, também deixava a maternidade de seu filho. Tudo em prol de uma causa que considerava maior e justa. Posteriormente, um membro do partido sugere que mantenha relações sexuais com um desconhecido para obter informações. Ela reconhece que pedem a sua prostituição. Ainda assim o faz. Pela causa que acha justa e maior do que qualquer outra coisa.

A relação entre Pagu e o Partido Comunista foi sempre conturbada. Ela tentava se adequar aos seus parâmetros para ser aceita, o que não conseguiu; posteriormente, se desvincula totalmente dele e

${ }^{6}$ CORRÊA. Mariza. A propósito de Pagu. Cadernos Pagu. Campinas, n. 1, 1993. Disponível em: http://periodicos.sbu.unicamp.br/ojs/index.php/cadpagu/issue/view/180/showToc. Acesso em: 28/12/2016.

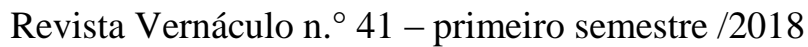

ISSN $2317-4021$ 
associa-se ao Partido Socialista, pelo qual tenta se eleger deputada estadual em 1950.

É ainda à sombra da conturbada relação com o Partido Comunista que publica, em 1933, Parque Industrial, sob o pseudônimo de Mara Lobo ${ }^{7}$. O livro foi escrito e publicado dentro da ótica e da estética modernista com a qual Pagu se relacionava intimamente. Assim, com essa obra a autora investe contra o establishment acadêmico e político e retoma uma das questões que caracterizam a literatura moderna: a invenção de linguagem ${ }^{8}$, aspecto que, segundo alguns estudiosos, teria herdado de Oswald, que, também em 1933, lançou Serafim Ponte Grande, cujo modelo de linguagem assemelha-se à obra de Pagu.

O primeiro livro de Pagu tem o intuito de alertar e indignar o leitor. ${ }^{9}$ Ele não se enquadra na estética defendida pelo partido, que deveria culminar na edificação e idealização da classe operária. Esta aparece no romance e é a personagem principal, sobretudo a mulher operária, o que também é considerado como uma revolução literária $a$

7 GALVÃO, Walnice Nogueira. Indômita Pagu. Disponível em: http://www.museusegall.org.br/pdfs/texto_Walnice_Nogueira_Galvao.pdf. Acesso em: 28/07/2017.

${ }^{8}$ CORRÊA, . Mariza. A propósito de Pagu. Cadernos Pagu. Op. Cit.

${ }^{9}$ HIGA, Larissa Satico Ribeiro. As representações da violência em Parque Industrial, de Patrícia Galvão. Disponível em: http://www1.lanic.utexas.edu/project/etext/llilas/ilassa/2008/higa.pdf. Acesso em: 28/07/2017.

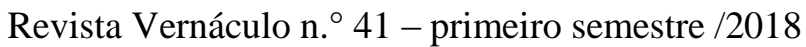

ISSN 2317-4021 
posteriori, pois à sua época o livro não foi compreendido e Pagu foi marginalizada pela crítica e pela historiografia. ${ }^{10}$

De fato, num primeiro momento, o romance causa desconforto, porque não se estrutura nos moldes dos romances que estamos acostumados a ler, isto é, os romances disseminados pelo cânone. O livro é arquitetado como um romance panfletário em que a linguagem real dos proletários do Brás, bairro industrial de São Paulo, é exposta não só para demonstrar a realidade, mas também para compor o ritmo narrativo que caracteriza de forma negativa a modernidade.

Porém, não só a linguagem é colocada à tona. Pode-se dizer que o livro trata da violência. Ele apresenta o cotidiano violento das proletárias, sujeitas ao descaso dos patrões e às investidas sexuais deles e de quaisquer outros, como são os casos de Corina e Matilde. Esta perde o emprego na fábrica porque se recusou a ir ao quarto do chefe. Já o caso de Corina é retratado de forma mais alarmante. Ela envolve-se com Arnaldo e engravida. Pensa que ele irá assumi-la juntamente com a criança. Isto não se realiza e é expulsa de casa pelo padrasto. Sem conseguir se manter, pois a gravidez é um empecilho para que continue na fábrica, acaba em um bordel, onde sonha com o berço da criança:

${ }^{10}$ SILVA, Valquíria Lima. As imagens no romance Parque Industrial: conflitos e pulsações da cidade moderna. Caderno de Literatura, v. 3, n. 5. Disponível em: http://www2.uefs.br/ppgldc/publicacoes/cad.lit.div.n5_071-88.pdf. Acesso em: 28/07/2017.

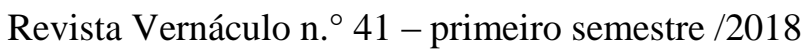

ISSN 2317-4021 
"Corina abre a porta, fatigada. Mais outro, e terá o dinheiro para o berço do filhinho". 11

Do bordel passamos às casas de parir, onde Pagu intercala as cenas de nascimento dos filhos das burguesas e das pobres proletárias que sequer têm sobrenome, como "quase todas as indigentes". ${ }^{12} \mathrm{~A}$ descrição do parto é propositalmente grotesca:

Lá no fundo das pernas um buraco enorme se avoluma descomunalmente. Se rasga, negro. Aumenta. Como uma goela. Para vomitar de repente, uma coisa viva, vermelha.

A enfermeira recua. A parteira recua. O médico permanece. Um levantamento de sobrancelhas denuncia a surpresa. Examina a massa ensanguentada que grita sujando a colcha. Dois braços magros reclamam a criança.

- Não deixe ver!

- É um monstro. Sem pele. E está vivo!

- Esta mulher está podre...

Corina reclama o filho constantemente. Tem os olhos vendados, o chorinho do monstro perto dela. ${ }^{13}$

Corina foi presa por aborto. O mesmo aborto que a sua chefe pediu que fizesse para manter o emprego. Ela se recusa a matar o seu filhinho, perde o emprego, se prostituiu para sobreviver e comprar o berço.

Pagu parece querer demonstrar um círculo vicioso social. A sociedade que impôs a Corina essa situação é a mesma que a pune por

${ }^{11}$ GALVÃO, Patrícia. Parque Industrial. São Paulo: Editora Cintra, 2003. Versão Kindle, p. 681.

${ }^{12}$ Idem, p. 718.

${ }^{13}$ Idem, p. 727-730.

Revista Vernáculo n. ${ }^{\circ} 41$ - primeiro semestre /2018

ISSN 2317-4021 
algo que ela não cometeu. É extremamente provável que a doença da qual sofre seu filho tenha sido provocada por uma doença transmitida sexualmente à qual Corina foi exposta por não se aceitarem mulheres grávidas para trabalhar. O pai da criança, Arnaldo, é mencionado em um episódio posterior como tendo se desenroscado da situação, ao dizer que o filho não era dele e já adornado nos braços de outra. “ - E a crioula? - Cadeia." ${ }^{\prime 14}$.

Com esse jogo de cenas e de palavras, a autora expõe, portanto, as diferentes facetas da violência que as mulheres proletárias sofriam. Tal ferramenta também pode ser verificada no jogo de cenas entre os nascimentos das crianças. Enquanto o parto de Corina é descrito como uma monstruosidade, a maternidade burguesa é glorificada:

É aquela mulata indigente que matou o filho!

- Estúpida! Só para não ter o trabalho de criar!

Vagabunda! Devia morrer na cadeia...

- Deixe, querida! Vê o nosso bebezinho que maravilha! Que gorducho! Olha as covinhas... Que saúde! $!^{15}$

Um dos elementos que trazem originalidade à obra de Pagu é justamente a ênfase nas questões femininas, tendo como um dos eixos ideológicos a condição social da mulher, colocando-se num panorama

${ }^{14}$ Idem, p. 845.

${ }^{15}$ Idem, p. 733-734.

Revista Vernáculo n. ${ }^{\circ} 41$ - primeiro semestre /2018

ISSN 2317-4021 
de crítica mais amplo que o feminismo burguês e anarquista, por ela criticados. ${ }^{16}$

Nos primórdios do século XX existiam, basicamente, duas vertentes feministas no Brasil: a bem e a mal comportada. ${ }^{17}$ A vertente bem comportada era liderada pelas mulheres liberais burguesas, entre as quais encontrava-se Bertha Lutz (1894-1976), líder da Federação Brasileira Pelo Progresso Feminino, cujo objetivo era a extensão dos direitos civis e políticos às mulheres. Acreditavam que pela educação e melhores empregos, as mulheres mudariam sua condição social e seriam reconhecidas pelo valor e talento. Ainda assim, Pagu faz uma ferrenha crítica a esse movimento em Parque Industrial:

As ostras escorregam pelas gargantas bem tratadas das líderes que querem emancipar a mulher com pinga esquisita e moralidade. ${ }^{18}$

(...)

- O voto para as mulheres está conseguido! É um triunfo!

- E as operárias?

- Essas são analfabetas. Excluídas por natureza. ${ }^{19}$

Por sua vez, a vertente feminista mal comportada tinha consciência da necessidade de uma transformação social mais profunda,

16 HIGA, Larissa Satico Ribeiro. As representações da violência em Parque Industrial, de Patrícia Galvão. Op. Cit.

${ }^{17}$ HIGA, Larissa Satico Ribeiro. O feminismo solitário na obra da jovem Pagu. Disponível

em:

https://www.academia.edu/4260371/HIGA_Larissa_Satico_Ribeiro._O_feminismo_so lit\%C3\%A1rio_na_obra_da_jovem_Pagu. Acesso em: 27/12/2016.

${ }^{18}$ GALVÃO, Patrícia. Parque Industrial. Op. cit, p. 875.

${ }^{19}$ Idem, p. 882-884.



ISSN 2317-4021 
não atingida apenas com o voto feminino. Dessa vertente participava o movimento anarquista que, contudo, também era criticado por Pagu, que foi a primeira mulher no Brasil a criticar o feminismo em nome do materialismo histórico dialético ${ }^{20}$, abordando um campo mais vasto de discussão, como a educação das mulheres, que deveria incluir a educação sexual, além de lutar contra a dominação dos homens e seu interesse em deixar a mulher fora do mundo público.

Diante disso, percebe-se que Pagu tece o livro através de temas que estão intimamente relacionados: a sexualidade, a opressão feminina, o aborto. Situações que Pagu apresenta como corriqueiras para as mulheres pobres. Situações por ela mesma vivenciadas, como o aborto pelo qual passou aos 14 anos, cujo testemunho em uma carta escrita a Geraldo Ferraz não se distancia muito da descrição do parto de Corina:

O ladrilho pegajoso nos lábios. O que fazer de tanto sangue? Todo o corpo se deformando. Se desfazendo na angústia. $O$ sangue ostensivo entre os dedos, cabelos, olhos, os coágulos monstruosos entupindo tudo. É preciso não deixar esse sangue. É preciso beber esse sangue. Como não morri no auge da

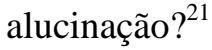

${ }^{20}$ HIGA, Larissa Satico Ribeiro. O feminismo solitário na obra da jovem Pagu. Op. cit., p. 3.

21 FERRAZ, Geraldo (org.). Paixão Pagu: A autobiografia precoce de Patrícia Galvão. Rio de Janeiro: Agir, 2005, p. 55.

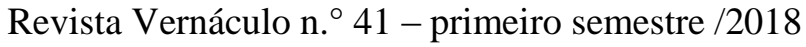

ISSN 2317-4021 
Posteriormente, já em relacionamento com Oswald de Andrade, ela passa por um novo aborto, também descrito de forma dramática a Geraldo:

Um dia matei a criancinha. Eu nada sabia dos cuidados que meu estado exigia. Eu ansiava por movimento e naquela tarde eu me atirei no rio Pinheiros. A correnteza era muito forte. Eu não conseguia alcançar mais a margem. Uma hora de luta com as águas. A Lurdes pediu socorro. Os homens da balsa não quiseram prestar auxílio, porque o rio ali era perigoso. Quando consegui sair do rio, já noite, todo o mal estava feito. Ainda a caminhada até em casa, as dores, a roupa molhada. Fui para a maternidade. Todos os brinquedos que já havia comprado. $\mathrm{O}$ cadaverzinho. As crianças nascendo normalmente ao meu lado. [...] Túmulo 17 - rua $17 .^{22}$

Evidentemente que não se pode compreender Pagu através de Parque Industrial, que não é uma obra autobiográfica. Contudo, através das investidas em seu depoimento autobiográfico, é impossível não visualizar a forte simbiose entre literatura e realidade por ela vivenciada. Não só de Pagu, mas das proletárias das quais se tornou porta-voz para denunciar a dura realidade propiciada pelo capitalismo e pelo patriarcado.

Nesse sentido, é possível identificar ações e destinos de personagens do livro em sintonia com a realidade vivenciada pelos agentes reais da luta política na qual a autora estava inserida. Ainda no que diz respeito às investidas sexuais que as mulheres sofriam pelos ${ }^{22}$ Idem, p. 61.

Revista Vernáculo n. ${ }^{\circ} 41$ - primeiro semestre /2018 
homens, em Paixão Pagu ela denuncia por diversas vezes as investidas a que foi submetida, inclusive por amigos próximos. Um deles, Cirilo, disse que quando Pagu passava na rua, todos os homens a desejavam e, por isso, ela nunca despertaria um sentimento puro de ninguém. ${ }^{23}$

Pode-se compreender, portanto, porque a sexualidade está presente como um dos eixos que norteiam as ações em Parque Industrial. Pagu diz que "sempre foi vista como um sexo"24, o que também ocorria com as proletárias do parque industrial do Brás, cujo caso mais sintomático é o de Corina, que é vista como sexo e por isso mesmo é punida moral, social e criminalmente, enquanto Arnaldo segue a vida sem nenhuma mancha, nos moldes da sociedade patriarcal e machista da época.

Parque Industrial também dá testemunhos sobre a militância através das personagens de Otávia e Rosinha Lituana. Esta, cujo nome remete a Rosa de Luxemburgo (1871-1919), é a responsável por explicar, logo no início do livro, os mecanismos da exploração capitalista. Ela também é responsável por discursar sobre o assunto em uma reunião de militantes. Tal fato é o que a leva presa, uma vez que é denunciada por Pepe em troca de 10 mil réis com os quais compra um presente para tentar reatar sua relação amorosa com Otávia, que também é presa e passa 6 meses degredada em uma colônia, medida iniciada no Brasil como repressão à Revolta da Vacina, em $1904^{25}$,

\footnotetext{
${ }^{23}$ Idem, p. 59.

${ }^{24}$ Idem, p. 139.
}

${ }^{25}$ HIGA, Larissa Satico Ribeiro. As representações..., Op. cit.

Revista Vernáculo n. ${ }^{\circ} 41$ - primeiro semestre /2018 
enquanto Rosinha, estrangeira, é deportada, ação intensificada no governo de Vargas, como atesta a própria Pagu em sua carta autobiográfica, quando diz que "todos os presos estavam sendo deportados para o exterior ou para as colônias". ${ }^{26}$

Ainda Otávia renunciará à sua relação com Alfredo, burguês proletarizado, acusado de ser trotskista, corrente contrária à do Partido Comunista Brasileiro, que enveredava ao leninismo. Assim, Otávia diz que ele é seu companheiro, mas se é um traidor o deixará. ${ }^{27}$ Da mesma forma, Pagu sacrificou sua relação com Oswald, uma vez que o partido o considerava suspeito por conta de suas relações com certos burgueses. Pagu e Otávia sacrificam-se pelo ideal que consideravam superior.

Pagu foi "a militante do ideal" 28 e, por esse motivo, de acreditar fielmente na causa pela qual lutava, surge Parque Industrial, cujo objetivo era ser um "livro revolucionário". ${ }^{29}$ A revolução não foi reconhecida no período e por muitos anos Pagu, enquanto escritora, foi relegada ao esquecimento, visto o fato da segunda edição de Parque Industrial ter sido feita somente na década de 1980. O livro causou incômodo justamente por explicitar os problemas sociais então vigentes e também por ter sido escrito numa linguagem bastante incomum, sobretudo para mulheres. O livro foi rejeitado também por não conter nenhuma heroicização do homem proletário, estética literária defendida pelo Partido Comunista.

${ }^{26}$ FERRAZ, Geraldo (org.). Paixão Pagu. Op. cit., p. 94.

${ }^{27}$ Idem, p. 1282.

${ }^{28}$ GALVÃO, Patrícia. Parque Industrial. Op. cit., p. 40.

${ }^{29}$ FERRAZ, Geraldo (org.). Paixão Pagu. Op. cit., p. 112.

Revista Vernáculo n. ${ }^{\circ} 41$ - primeiro semestre /2018

ISSN 2317-4021 
A análise da obra de Pagu, além de contribuir para a compreensão de uma perspectiva dos acontecimentos sociais, políticos e culturais dos quais foi testemunha e participante, também permite a análise através do viés do sentido da escrita de mulheres. Para Pagu, a escrita estava vinculada à ânsia da vida engajada. Nesse sentido, podemos questionar vertentes da crítica literária feminista que defendem uma essência da escrita feminina que contribuiu para uma maior diferenciação entre os sexos. Tal diferenciação ocorre, de fato, por conta das diferentes experiências de vida a que cada escritor está sujeito. Inseridas numa sociedade patriarcal e machista, as experiências de vida de uma mulher serão, de fato, mais restritas do que as dos homens. Contra isso, Pagu se insurgiu, mas não somente. Como dito anteriormente, o propósito de vida de Pagu era o engajamento social, cuja luta contra a visão sexual e inferior da mulher estava inserida dentro da sua perspectiva da luta de classes.

Por outro lado, pode-se dizer que a crítica literária feminista possibilitou a releitura de Pagu e a tentativa de compreender suas variadas facetas e não estigmatizá-la na lenda que criou sua imagem como irresponsável, "porra louca" e exibicionista, ${ }^{30}$ contribuindo para desconstruir estereótipos, comportamentos e o cânone literário.

Assim, podemos compreender a obra de Pagu como um marco da crítica social, na qual condena diversas práticas e instâncias, a começar pela estrutura capitalista que transforma a vida em trabalho,

${ }^{30}$ FERRAZ, Geraldo (org.). Paixão Pagu. Op. cit., p. 12.

Revista Vernáculo n. ${ }^{\circ} 41$ - primeiro semestre /2018

ISSN $2317-4021$ 
violência, frustração e hipocrisia, esta ilustrada na cena em que relata que o carnaval abafa e engana a revolta dos explorados. ${ }^{31}$

Parque Industrial é revolucionário, pois traz à tona uma realidade que por vezes tentava-se esconder. No período em que foi produzido estava em voga a ideologia de higienização, a partir da qual se tentava expulsar as camadas populares do centro das cidades. O Brás, em São Paulo, era considerado o bairro da degradação humana. E é este justamente o cenário da obra, que coloca em primeiro plano todos os personagens sociais que deveriam permanecer escondidos. Juntamente com os personagens, ela traz as consequências trágicas que uma parcela da população sofre por conta do processo de industrialização.

Ainda sob o aspecto literário, podemos pensar o livro de Pagu como um rompimento e uma crítica à ideia da "natureza feminina" e, portanto, da reprodução de estereótipos tanto nas personagens como na própria forma da obra e da concepção de escrita que, para Pagu, deveria ser engajada. À época do seu lançamento, talvez a única crítica positiva tenha sido de João Ribeiro (1860-1934), que reconhece Parque Industrial como um romance antiburguês, de onde a verdade ressalta involuntariamente das páginas veementes e tristes. ${ }^{32}$

Para Sartre, a escrita deve ser engajada no sentido de ser uma prática de desnudamento em que não importa somente o que o escritor escreveu, mas como escreveu. Assim, a forma da escrita é tão

${ }^{31}$ GALVÃO, Patrícia. Parque Industrial. Op. cit., p. 484.

32 CAMPOS, Augusto. Pagu. Patrícia Galvão. Vida-obra. São Paulo: Brasiliense, 1982, p. 282.

Revista Vernáculo n. ${ }^{\circ} 41$ - primeiro semestre /2018

ISSN $2317-4021$ 
consciente como a escrita em si, pois expõe o mundo através da criação literária com a intenção de que o leitor colabore em transformar o mundo. De fato, em Parque Industrial é possível perceber o desnudamento de Pagu e seu pacto com a causa para transformar o mundo. E, por não ser mulher pra se calar, foi esmagada. ${ }^{33}$

\section{Referências}

BELLIN, Greicy Pinto. A crítica literária feminista e os estudos de gênero: um passeio pelo território selvagem. Revista FronteiraZ, São Paulo, n. 7, dezembro de 2011. Disponível em: http://revistas.pucsp.br/index.php/fronteiraz/article/viewFile/12201/8846. Acesso em: 28/12/2016.

CAMPOS, Augusto. Pagu. Patrícia Galvão. Vida-obra. São Paulo: Brasiliense, 1982.

CORRÊA, Mariza. A propósito de Pagu. Cadernos Pagu, Campinas, n. 1, 1993. Disponível em: http://periodicos.sbu.unicamp.br/ojs/index.php/cadpagu/issue/view/180/showT oc. Acesso em: 28/12/2016.

DELGADO, Lucília de Almeida Neves; FERREIRA, Jorge (org.). O Brasil republicano. O tempo do nacional-estatismo: do início da década de 30 ao apogeu do Estado Novo. Rio de Janeiro: Civilização Brasileira, 2003.

FERRAZ, Geraldo (org.). Paixão Pagu. A autobiografia precoce de Patrícia Galvão. Rio de Janeiro: Agir, 2005.

GALVÃO, Patrícia. Parque Industrial. São Paulo: Editora Cintra, 2003. Versão Kindle.

${ }^{33}$ ZATZ, Lia. Pagu. São Paulo: Callis, 2005, p. 16.

Revista Vernáculo n. ${ }^{\circ} 41$ - primeiro semestre /2018

ISSN 2317-4021 
GALVÃO, Walnice Nogueira. Indômita Pagu Disponível em: http://www.museusegall.org.br/pdfs/texto_Walnice_Nogueira_Galvao.pdf. Acesso em: 28/07/2017.

HIGA, Larissa Satico Ribeiro. O feminismo solitário na obra da jovem Pagu. Disponível em: https://www.academia.edu/4260371/HIGA_Larissa_Satico_Ribeiro._O_femin ismo_solit\%C3\%A1rio_na_obra_da_jovem_Pagu. Acesso em: 27/12/2016.

As representações da violência em Parque Industrial, de Patrícia Galvão. Disponível em: http://www1.lanic.utexas.edu/project/etext/lilas/ilassa/2008/higa.pdf. Acesso em: 28/07/2017.

MOI, Toril. Teoria literaria feminista. Madri: Catedra, 1988.

PRIORE, Mary Del (org.). História das mulheres no Brasil. São Paulo: Contexto, 2009.

SARTRE, Jean-Paul. Que é a literatura? São Paulo: Ática, 2004.

SILVA, Valquíria Lima. As imagens no romance Parque Industrial: conflitos e pulsações da cidade moderna. Caderno de Literatura, v. 3, n. 5. Disponível em: http://www2.uefs.br/ppgldc/publicacoes/cad.lit.div.n5_071-88.pdf. Acesso em: 28/07/2017.

WIECHMANN, Natália Helena. A crítica literária feminista e a autoria feminina. Vocábulo. Revista de letras e linguagens midiáticas. Ribeirão Preto, v. $4 . \quad$ Disponível em: http://www.baraodemaua.br/comunicacao/publicacoes/vocabulo/volumeIV.ht ml. Acesso em: 28/12/2016.

WOOLF, Virginia. Um teto todo seu. São Paulo: Círculo do Livro, s/d.

ZATZ, Lia. Pagu. São Paulo: Callis, 2005.

Recebido em 30/04/2017, aceito para publicação em 28/07/2017.

Revista Vernáculo n. ${ }^{\circ} 41$ - primeiro semestre /2018

ISSN $2317-4021$ 